\title{
INTERthesis
}

DOUTORADO INTERDISCIPLINAR EM CIÊNCIAS HUMANAS - UFSC - FLORIANÓPOLIS - SC - BRASIL

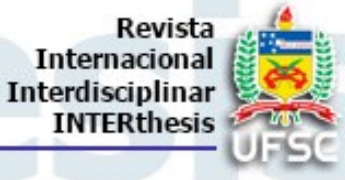

\section{GÊNESE, DÉMARCHE E DESENVOLVIMENTO DA ABORDAGEM NORMATIVA EM EPISTEMOLOGIA}

Valdirlen do Nascimento Loyolla ${ }^{1}$

\section{Resumo:}

O presente artigo tem como escopo principal mostrar a trajetória da abordagem normativa e suas diferentes variações temáticas diante dos mais diferentes ataques que esta tem sofrido ao longo da história da filosofia. Assim, busca-se tratar o itinerário filosófico-epistemológico acerca da abordagem normativa ou prescritiva do conhecimento desde as suas bases. A metodologia utilizada se estriba no método dialético, destacando no seio da própria abordagem normativa as diferentes concepções de normatividade e suas contraposições teóricas. A trilha metodológica utilizada centrou atenção na revisão bibliográfica de Platão, Descartes, Kant, Russell, Quine e Laudan, percorrendo as análises críticas concernentes aos aspectos epistemológicos normativos ao longo da história do conhecimento, fundamentalmente do conhecimento científico.

Palavras-chave: Epistemologia Normativa. Conhecimento Prescritivo. Normatividade no Conhecimento Científico.

\section{GENESIS, DÉMARCHE AND DEVELOPMENT OF THE NORMATIVE APPROACH IN EPISTEMOLOGY}

\begin{abstract}
:
The main purpose of this article is to show the trajectory of the normative approach and its different thematic variations regarding the most different attacks that it has suffered throughout the history of philosophy. Thus, it is sought to treat the philosophical-epistemological itinerary about the normative or prescriptive approach of knowledge from its bases. The methodology used is based on the dialectical method, emphasizing within the normative approach itself the different conceptions of normativity and their theoretical contrapositions. The methodological trail focus on the bibliographical review of Plato, Descartes, Kant, Russell, Quine and Laudan, covering the critical analyzes concerning normative epistemological aspects throughout the history of knowledge, fundamentally of scientific knowledge.
\end{abstract}

Keywords: Normative Epistemology. Prescriptive Knowledge. Normativity in the Scientific Knowledge.

\footnotetext{
${ }_{1}^{1}$ Doutor em Lógica e Filosofia da Ciência pela Universidade Federal de Minas Gerais. Professor do Departamento de Filosofia da Universidade Estadual de Montes Claros, MG, Brasil E-mail: valdirloyolla@yahoo.com.br
} 


\section{GÉNESIS, ANDAMIENTO Y DESARROLLO DEL ABORDAJE NORMATIVO EN EPISTEMOLOGÍA}

\section{Resumen:}

El presente artículo tiene como objetivo principal mostrar la trayectoria del enfoque normativo y sus diferentes variaciones temáticas ante los más diferentes ataques que ésta ha sufrido a lo largo de la historia de la filosofía. Así, se busca tratar el itinerario filosófico-epistemológico acerca del enfoque normativo o prescriptivo del conocimiento desde sus bases. La metodología utilizada se estriba en el método dialéctico, destacando en el seno del propio enfoque normativo las diferentes concepciones de normatividad y sus contraposiciones teóricas. La ruta metodológica utilizada centró la atención en la revisión bibliográfica de Platón, Descartes, Kant, Russell, Quine y Laudan, recorriendo los análisis críticos concernientes a los aspectos epistemológicos normativos a lo largo de la historia del conocimiento, fundamentalmente del conocimiento científico.

Palabras clave: Epistemología Normativa. Conocimiento Prescriptivo. Normatividad en el Conocimiento Científico.

\section{INTRODUÇÃO}

O problema da normatividade em Epistemologia também é conhecido como o problema da abordagem prescritiva no conhecimento. A origem de tal problema se remonta na antiguidade a Platão, a moderna a Descartes e Kant e a contemporânea aos filósofos analíticos. Assim, o escopo principal desse trabalho consiste em mostrar a trajetória da abordagem normativa e suas diferentes variações temáticas. Cumpre-nos também apresentar os mais diferentes ataques que esta tem sofrido ao longo da história da filosofia. Por exemplo, a solução platônica ao apontar que o conhecimento se diferenciava da crença verdadeira por ser justificado abre margens para uma série de ataques céticos.

De acordo aos céticos antigos, todas as tentativas de fornecer justificações adequadas para a crença (até mesmo para a crença verdadeira) eram incorrigivelmente dúbias, contraditórias e defeituosas. Nesse aspecto, se a justificação é a marca que distingue o conhecimento da crença verdadeira, pode-se concluir que as atribuições de conhecimento devem, em alguma medida, depender do 'contexto'. Contudo, se a abordagem tradicional está estribada na suposição de que as questões epistemológicas devem ser adequadamente respondidas de modo a não pressupor nenhum conhecimento particular, o ataque cético aponta para o fato de que buscar tal argumento obviamente recairá sob uma 'petição de princípio'.

No intuito de resolver o problema da passagem do âmbito particular de nossas crenças para o universal (conhecimento), de modo a não mais prescindir dos 
contextos, outra corrente de pensamento surge da tentativa de fornecer uma reconstrução do conhecimento explicitando como as 'partes do conhecimento' (crença, justificação, razões e verdade) se encaixam em uma 'estrutura formal ou metafísica' que Ihe serve de apoio ou fundamento. Esse novo projeto epistemológico tem a sua forma moderna em Descartes e assume uma 'forma lógica transcendental' mais arrojada em Kant, havendo também versões empiristas bem como racionalistas, que podem fazer uma viragem para os âmbitos fundacionista, coerentista ou analítico acerca do conhecimento - tais abordagens podem ser aqui denominadas de epistemologias transcendentais.

Grosso modo, tanto a epistemologia tradicional (platônica) quanto a transcendental (kantiana) pode ser inscritas sob a rubrica de epistemologia normativa, uma vez que as bases que sustentam a reconstrução do conhecimento são as relações (normas) de justificação (ou de prova) que devem permitir distinguir conhecimento de crença verdadeira.

As razões históricas que levaram a alteração da abordagem normativa tradicional do conhecimento para a transcendental podem ser pensadas como sendo devida a mudança do eixo explicativo do plano de conhecimento sob a forma de episteme para a forma de conhecimento teórico-experimental, conhecimento compreendido como scientia - isso devido ao nascimento da ciência moderna do século XVII.

Mediante o surgimento da ciência moderna da Natureza, que pode ser representada pelo modelo de investigação físico-matemática galileo-newtoniano, a reflexão epistemológica moderna a reconheceu como um tipo de conhecimento que punha em conflito as pretensões normativas da episteme clássica. O caráter experimental da ciência moderna (scientia) e o ideal de seu método em buscar expressar os fenômenos naturais em termos de leis universais exigiu uma completa reformulação da episteme tradicional.

A epistemologia normativa se constitui em um projeto que tem por objetivo esclarecer e defender concepções acerca do conhecimento pautadas em critérios como fundamento, regras, evidência, razões e justificação. Entretanto, a relevância de tão almejado método (epistemológico), capaz de validar e dar amparo sólido ao que pretendemos como conhecimento, tem se esbarrado em uma série de argumentos organizados como um conjunto de contraexemplos, que mostram que 'é possível ter uma crença verdadeira justificada sem que essa crença seja 


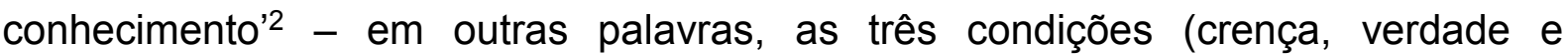
justificação) podem ser condições necessárias, mas não são suficientes para o conhecimento.

\section{O PROBLEMA DA DISTINÇÃO ENTRE 'CONHECIMENTO' E 'CRENÇA VERDADEIRA': A GÊNESE DA EPISTEMOLOGIA NORMATIVA}

A gênese do problema da distinção entre 'conhecimento' e 'crença verdadeira', dentro da 'teoria do conhecimento tradicional', pode ser remontada ao pensamento de Platão (427-348 a. C), configurando-se no antigo problema da filosofia clássica em distinguir doxa (opinião/convicção) de episteme (conhecimento justificado).

Em seu Diálogo Teetetos, Platão enumera três condições necessárias para que ocorra o conhecimento (episteme). A primeira condição platônica toma a noção de crença como ponto de partida para o conhecimento. Assim, qualquer sujeito que diz 'saber' alguma coisa deve, primeiramente, acreditar nessa mesma coisa. A segunda condição necessária para que ocorra o conhecimento é a verdade.

Uma crença pode se mostrar ser verdadeira ou falsa, mas uma crença falsa não conduz ao conhecimento daquilo que a crença postula, e, nesses termos, por consequência, o foco da atenção platônica recaia sobre a noção de crença verdadeira. Mas a posse da crença verdadeira ainda não é conhecimento, porque podemos ter a crença em 'algo' e esta se mostrar ser verdadeira por 'acaso' ou por 'coincidência'.

A ocorrência do acaso ou de uma coincidência que possa infirmar a verdade de uma crença requer, para a correta distinção entre crença verdadeira e conhecimento, a introdução da justificação (prova) como uma terceira condição necessária para que haja o conhecimento.

Por conclusão, a inferência platônica acerca das três condições pensadas simultaneamente deseja estabelecer de modo necessário que uma crença verdadeira somente tornar-se-á conhecimento se esta puder ser justificada. A justificação, tomada nesse aspecto, consistiria na 'razão' ou em um 'conjunto de razões' que suportaria a verdade da crença. O corolário final dessa tese pode ser assim equacionado: 'só pode haver conhecimento daquilo que se pode justificar, não

${ }^{2}$ Acerca dessa questão, a partir de uma análise puramente lógica, vide os trabalhos de Edmund Gettier, especialmente, "Is justified true belief knowledge?". 
podendo haver conhecimento do que não é possível justificar'. Esta, portanto, seria a definição padrão amplamente aceita de conhecimento que funda a epistemologia tradicional, cujo interesse consistia no problema de distinguir entre 'conhecimento' e 'crença verdadeira' pautando-se em critérios de 'justificação'.

\section{CONHECIMENTO COMO CRENÇA VERDADEIRA}

O problema exposto nos parágrafos anteriores pode ter a sua origem na própria noção de 'conhecimento', de 'crença verdadeira' e na noção de 'razões' amparadas pelas evidências capazes de aumentar ou suportar a verdade da crença. No âmbito geral do conceito de crença podemos entendê-lo de acordo ao 'binômio': crença 'falsa' e crença 'verdadeira'. Porém, uma crença que se mostra ser falsa não conduz ao conhecimento daquilo que a crença postula; mas isso não quer dizer que a crença falsa não conduz a nenhum tipo de informação.

A informação derivada da crença falsa pode ser compreendida como um tipo de informação fraca ou informacional mínimo, no sentido de que aquilo que a falsidade da crença informa é que apenas o que foi postulado se mostrou ser falso. Há certo 'ganho' nisso, mas o ganho epistêmico que se tem com a informação gerada pela crença falsa oferta pouca rentabilidade para o desenvolvimento do conhecimento. Nesses termos, portanto, o foco da análise deve recair simultaneamente sobre o que doravante deve ser pensado como sendo o conceito próprio de conhecimento justificado necessariamente atrelado à outra parte do 'binômio crença', isto é, relacionado à noção de crença verdadeira. Mas, a simples posse da crença verdadeira ainda não é garantidora de conhecimento em sentido forte, porque podemos ter a crença em 'algo' e esta se mostrar ser verdadeira por 'acaso' ou por 'coincidência'.

Ao que parece, a ocorrência do acaso ou da coincidência frustra as expectativas para que a crença verdadeira seja elevada a condição de conhecimento em sentido forte, gerando um tipo de conhecimento que poderíamos aqui denominar de conhecimento esotérico. Entretanto, isso não significa dizer que não há também um ganho informacional na forma de conhecimento gerada pela ocorrência do acaso ou da coincidência, o seu resultado pode vir a ofertar certa 'positividade' ao âmbito do conhecimento, mesmo levando em consideração o 
'caráter esotérico', obscuro ou não manifesto de sua evidência que não pode ou não permite ser explicitado ou justificado em razões.

A exigência epistemológica normativa determina que o laço que deve atrelar a crença verdadeira ao conhecimento em seu sentido forte deve ser, por conseguinte, a justificação estribada em razões capazes de suportar a verdade da crença. Tais razões, aqui denominadas de razões epistêmicas, devem referir-se tão somente às que estão sempre embasadas nas evidências que nos levam a 'acreditar' no que julgamos verdadeiro.

Por conclusão, a análise operacionalizada sobre o conceito geral de crença descarta aquelas crenças que ofertam uma tipologia de conhecimento cujas razões não podem ser amparadas por nenhuma evidência. A consequência direta dessa concepção é que o sentido forte do conhecimento, exigido pela epistemologia normativa, ficará subordinado a algum tipo de dependência que o conhecimento e sua justificação possam ter do contexto - o que, para muitos, gera alguma forma de relativismo (epistêmico, ontológico ou linguístico) ${ }^{3}$.

A consideração de que as atribuições de conhecimento dependam do contexto, porque os padrões adequados de justificação devem depender do contexto, desencadeia no plano da epistemologia normativa uma série de problemas de fundamentação do conhecimento.

Em nosso entendimento, o problema acima apresentado pode ser devido à existência de dois projetos epistemológicos distintos que, historicamente, conformam a epistemologia normativa: de um lado a epistemologia (normativa) tradicional calcada no pensamento platônico, cujo modelo é extraído da matemática, fundamentalmente da aritmética e da geometria de Euclides; e, de outro, a epistemologia (normativa) transcendental, originária do pensamento cartesianokantiano, cujo modelo explicativo buscou a sua forma mais acabada na física, em especial na física de Newton.

$\mathrm{Na}$ contemporaneidade, o aspecto da transcendental da epistemologia normativa, sofrerá uma série de reformulações por parte da corrente denominada de neopositivismo devido aos pressupostos da física de Einstein e, mais tardiamente, as questões advogadas pela física quântica; de um modo ou de outro, salvaguardando as devidas proporções históricas, o modelo da epistemologia 
normativa transcendental permanecerá sendo orientado por algum tipo de 'matriz de ordem física' para a compreensão do conhecimento até a segunda metade do século $X X$.

\section{A EPISTEMOLOGIA NORMATIVA TRADICIONAL}

A epistemologia normativa tradicional, considerada aqui como uma primeira forma de exame sistemático do conhecimento, transfere para o plano do 'conhecimento comum' toda a estrutura formal estipulada nas regras da matemática, no intuito de validar e dar amparo sólido ao que se pretende conhecer, independente de nossos posicionamentos particulares.

A objetividade do conhecimento verdadeiro, assim pretendida, busca interditar todas as formas de crenças que poderiam ser legitimadas e relativizadas a um contexto, intentando possibilitar um conhecimento universal de referência para todas as crenças justificadas - esse aspecto do método em questão pode ser a causa de um tipo de 'relativismo' de cunho epistêmico-moral, cuja forma sofística pode ter a sua origem em Protágoras (487-412 a. C), segundo o qual "a verdade (da crença) seria relativa aos (contextos dos) indivíduos"4. Nesse sentido, essa forma de relativismo (que também dá margem ao ceticismo) se estriba na recusa de que possam existir quaisquer 'valores universais' que fundamentem ou justifiquem o conhecimento, sejam estes valores epistêmicos ou morais.

No quadro de referência das crenças, estipulado pela epistemologia normativa tradicional, tanto as 'crenças falsas' quanto as 'crenças verdadeiras, cujo conhecimento se dá pelo acaso ou coincidência', são geradoras de algum tipo de conhecimento ou informação, mas que não podem ser adotados como conhecimento em sentido forte porque Ihes falta a normatividade necessária e universal da justificação. Nesse sentido, tais crenças estariam no mesmo patamar do 'conhecimento comum' ou ordinário.

Da perspectiva do conhecimento comum sabemos muita coisa, sobre o que vemos e o que não vemos, sobre coisas esotéricas e controversas, e duvidar disso ou relativizar, mesmo de modo sério ou filosófico, pode, em um primeiro momento parecer um absurdo. Mas, quando nos colocamos na perspectiva da epistemologia normativa tradicional deparamos com um argumento forte de que 'o que sabemos é

${ }^{4}$ Cf. PLATÃO. Teetetos, 2001, 152a-152e, 49-50. 
muito pouco', uma vez que nossas crenças verdadeiras precisam ser justificadas ou provadas com base em evidências e apoiadas em razões epistêmicas. Nesse sentido, o argumento cético ou relativista nem é tão demolidor, porque a cláusula que eles propõem é que o conhecimento deve ser por definição infalível e do qual se elimine todas as possibilidades de erro. Essa exigência é a mesma defendida pela epistemologia normativa tradicional.

Talvez, a exigência de infalibilidade do conhecimento se deva ao fato de que conhecimento infalível somente é possível acerca de verdades necessárias simples, axiomáticas, que se configuram como critérios, normas e regras que fundamentam a matemática e são utilizadas como modelo padrão pela epistemologia normativa tradicional.

A metodologia estipulada pela epistemologia normativa tradicional, quando busca precisar o conhecimento em seu sentido forte, o faz dentro de um quadro de referência que tem nas razões epistêmicas o próprio padrão de universalidade exigido para se avaliar ou justificar os valores (crença) epistêmicos, deixando de fora de seu quadro de referência as razões não epistêmicas e pragmáticas - as primeiras seriam aquelas razões que nos fazem acreditar em 'algo' tendo por base algum tipo de ideologia ou fundadas no medo, no respeito, na cultura, na autoridade, no dinheiro, no gênero entre outras; e, as segundas, não estabelecem a verdade da crença, mas apenas das vantagens pragmáticas de tê-la.

Contudo, sendo as 'razões das crenças' classificadas em diferentes modelos, a pertinência e a plausibilidade de nossas justificativas podem não mais corresponder ao nosso julgamento quando confrontadas com novas evidências. Esse ponto, em especial, não concorda que a marca do conhecimento seja a justificação, pelos seguintes aspectos:

a) nenhuma justificação é suficientemente boa, porque não há justificação que chegue a um argumento dedutivo sólido;

b) a justificação não é sempre necessária, porque adquirimos conhecimento por meios que não podem ser justificados por evidências;

c) por elevar os nossos padrões de conhecimento para a justificação, a epistemologia normativa tradicional torna o 'conhecimento esquivo';

d) estabelecer o conhecimento pautado somente em seu sentido forte, justificado, é abrir mão de uma gama de explicações que 'empobrecem' o campo epistemológico; nesse sentido, a epistemologia normativa tradicional 
além de tornar o conhecimento esquivo também destrói o seu próprio objeto de estudo.

Destarte, havemos de saber se o conhecimento é naturalmente esquivo ou se o problema de sua esquivocidade é gerado pela própria normatividade das regras de justificação que a ele é imposta. De um modo ou de outro, não buscar a justificação necessária do conhecimento, 'aceitando o relativismo', é ter "medo do conhecimento" 5 .

O choque gerado pelo confronto das considerações elencadas, nos itens de "a" a "d" anteriormente mencionados, somente poderia ser atenuado se pudéssemos anular a conexão entre o conhecimento e a justificação. Mas, se assim o fizermos, o conhecimento em seu sentido forte deixara de possuir aquele desejo humano de conhecer as possibilidades de como é o mundo ou as possibilidades "reais" que estruturam e conformam as leis da Natureza.

O novo giro epistemológico que deve agora ser operado sobre a epistemologia normativa tradicional consiste em fundar na própria estrutura do sujeito cognoscente as condições de possibilidades para o conhecimento - nesse sentido, a epistemologia normativa tradicional se converte na epistemologia normativa transcendental - um tipo de epistemologia cujo modus operandi adotará a normatividade da matemática, mas cujo modelo se estriba nos pressupostos de conhecimento oriundos de uma matriz de ordem física.

\section{A EPISTEMOLOGIA NORMATIVA TRANSCENDENTAL}

O mecanismo explicativo adotado pela epistemologia normativa transcendental deve fornecer uma reconstrução do conhecimento explicitando como as 'partes do conhecimento' se encaixam em uma 'estrutura' que serve de apoio mútuo entre os âmbitos formais (necessários e universais) e empíricos (particulares e contingentes) do conhecimento.

Esse novo projeto epistemológico segue as pistas deixadas pela 'epistemologia normativa tradicional', e se constitui em um modelo que tem por objetivo esclarecer e defender concepções acerca do conhecimento pautadas também em critérios como fundamento, regras, evidência, razões e justificação, 
porém centradas na estrutura formal (a priori) do sujeito cognoscente - seja esta estrutura a 'mente', o 'sujeito transcendental' ou a 'linguagem'.

As razões históricas que levaram a alteração da abordagem normativa tradicional do conhecimento para a transcendental podem ser pensadas como sendo devida a mudança do eixo explicativo do plano de conhecimento sob a forma de episteme para a forma de conhecimento teórico-experimental, conhecimento compreendido como scientia - isso devido ao nascimento da ciência moderna do século XVII.

Mediante o surgimento da ciência moderna da Natureza, que grosso modo pode ser representada pelo modelo de investigação físico-matemática galileonewtoniano, a reflexão epistemológica moderna a reconheceu como um tipo de conhecimento que punha em conflito as pretensões normativas da episteme clássica. O caráter experimental da ciência moderna (scientia) e o ideal de seu método em buscar expressar os fenômenos naturais em termos de leis universais exigiu uma completa reformulação da episteme tradicional.

O racionalismo moderno procurou situar essa nova forma de conhecimento dentro de um quadro de racionalidade que pressupunha a 'certeza' e a 'universalidade' como sendo suas características fundamentais. Por outro lado, o empirismo moderno procurou enquadrá-lo como um tipo de conhecimento cuja essencialidade ainda era devedora da experiência ordinária.

Ao considerar que todo conhecimento factual tem sua origem na experiência imediata, o empirismo passou a negar a possibilidade de se atribuir as leis das ciências experimentais características como a universalidade estrita, algo que não pode ser inferido e não se deixa explicar pela experiência.

A contraposição racionalista vai considerar que desde que existam leis universais e necessárias nas ciências empíricas, estas não podem ser justificadas com base exclusivamente calcadas na experiência - o que vai requerer que se estabeleça algum tipo de princípio fundado na estrutura da razão, como as 'ideias inatas' cartesianas, as 'impressões' humeanas, o 'a priori' kantiano ou os 'juízos analíticos e semânticos' dos neopositivistas.

Interessante é notar que o modelo epistemológico padrão adotado na modernidade pela epistemologia normativa transcendental, seguirá, inicialmente, as marcas explicativas e os resultados da física de Galileo e Newton, passando na contemporaneidade a assumir o modelo explicativo oriundo das descobertas e dos 
resultados da física de Einstein e da mecânica quântica. No geral, a ciência será o 'modelo de racionalidade' que perpassará toda a modernidade até a segunda metade do século $\mathrm{XX}$, e terá a sua forma epistemológica mais bem acabada nos pressupostos analíticos da corrente filosófica denominada de neopositivismo. Nesse sentido, a epistemologia passou a ser entendida e considerada como a teoria do conhecimento científico.

A tradição epistemológica transcendental que une Descartes e Kant, bem como Russell, Quine e toda corrente analítica, pode ser pensada como uma tradição de pesquisa que procurou resolver o problema da dualidade corpo-mente ou o problema analítico-sintético, ou mais contemporaneamente o problema do 'realismo' versus 'antirrealismo' (por exemplo, sob a forma de idealismo e construtivismo).

Quando Kant se celebrizou por negar, na Crítica da razão pura (1781), 'que o mundo, tanto quanto podemos conhecê-lo, pudesse ser independente dos conceitos por meio dos quais nós o aprendemos' ${ }^{\prime}$, ele não somente ratificou o idealismo platônico na modernidade como o incorporou à subjetividade do sujeito cartesiano limitando as possibilidades "diretas" de se falar de um conhecimento objetivo acerca do mundo, da realidade ou da Natureza.

No sentido exposto acima, a epistemologia kantiana estabelece que a derivação empírica que Hume propõe dos conceitos puros não pode ser posta de acordo com a realidade dos conhecimentos científicos a priori que possuímos, (isto é, os conceitos da matemática pura e da ciência universal da Natureza), sendo, portanto, refutada pelo fato ${ }^{7}$ - uma tentativa de superar tal problema será proposta pelo neopositivismo.

O construtivismo kantiano ao estabelecer a noção filosófica de um 'sujeitoconstituidor-do-mundo', 'de um mundo conceitualmente construído' ou 'de um mundo dependente de uma mente' funda um tipo de antirrealismo no qual a epistemologia transcendental apresenta sérias dificuldades em localizar a estrutura normativa do conhecimento em algum lugar no mundo "material" ou "real", restando apenas a esta avaliar lógica ou analiticamente o conjunto abstrato de proposições e suas relações que intentam representar o mundo. 
Mas, de qual mundo estamos agora falando? De um 'mundo subjetivo' autorrepresentado nas estruturas proposicionais ou conceituais do sujeito cognsocente, ou de um 'mundo objetivo' e perceptual?

Uma saída epistemológica possível para o questionamento supracitado foi levar o problema para o campo de análise do conhecimento científico, mais especificamente utilizando-se uma matriz de ordem física como modelo epistemológico. Porém, os objetivos do epistemólogo quando avalia o conhecimento podem não ser os mesmos do cientista quando elabora uma teoria e a partir desta tenta explicar o mundo. O mundo do cientista configura-se no mundo "real", é este que ele deseja explicar e expressar através de suas teorias ${ }^{8}$. Entretanto, dirá o epistemólogo, utilizando-se de um jargão normativo transcendental de cunho analítico: "Mas não são as teorias proposições elencadas sobre o mundo? E não são tais proposições constituídas de entidades ou termos teóricos?" - assim, ficamos a meio caminho entre o realismo e o antirrealismo quando tentamos reduzir proposições gerais a objetos evidentes, particulares e sensoriais: o conhecimento mais uma vez se esquiva.

\section{NORMATIVIDADE E RELATIVISMO EPISTÊMICO}

Retrospectivamente, o problema abordado na seção anterior nos faz observar que o comprometimento da 'epistemologia normativa tradicional' com o idealismo (platônico) assume um caráter similar ao da 'epistemologia normativa transcendental' quando esta assume a sua forma de análise proposta por um ideal construtivista (de feitio kantiano). De um modo ou de outro, essas formas de abordagens normativas sempre exibirão algum relativismo epistêmico todas as vezes que tentamos justificar proposições gerais com base em casos particulares.

A epistemologia normativa transcendental do neopositivismo ao tentar romper com o antirrealismo, propondo uma explicação objetiva para o conhecimento

\footnotetext{
'Geralmente, o que se quer dizer por 'uma realidade independente' é que a existência do 'mundo' não é causada pela mente, no sentido de que há um 'substrato real' que a mente humana não cria pelo simples fato de tentar conhece-lo e que persistiria do mesmo modo em sua existência, mesmo, se acaso, não houvesse nenhuma mente humana. Poucos antirrealistas e construtivistas sociais contemporâneos negariam tal tese, pois que a negação dessa tese conduz diretamente ao 'solipsismo' ou ao 'idealismo'. Com referência a epistemologia kantiana, a realidade do mundo exterior não é algo meramente hipotético para o seu idealismo (antirrealismo ou construtivismo), mas algo totalmente objetivado pelos juízos sintéticos a priori [KANT (1781), 2001, B17-B18, 74-75]. O realismo ontológico sustentado pela ciência moderna não pode ser identificado com a postulação de uma realidade noumênica e, portanto, permanentemente inacessível.
} 
científico em termos de conhecimento lógico-proposicional concedeu aos seus críticos o direito de afirmarem que o método proposto nada mais faz do que ratificar o antirrealismo, no sentido de que 'se o mundo se constitui em um conjunto de proposições, o conhecimento científico nada mais é que o resultado de se verificar proposições a partir de proposições' - nesse sentido, o conhecimento não somente mais uma vez se esquiva, como deixa de fora da ciência uma série de proposições que não podem ser verificadas.

A tese epistemológica de que o significado de uma proposição é dado pelo critério da verificação, se este puder estabelecer o conteúdo de verdade ou falsidade, consiste em uma tentativa neopositivista de pautar os rigores da lógica dedutiva contra qualquer tentativa de reificação da linguagem natural como um tipo de linguagem adequada ao conhecimento científico. Mesmo que a instância de justificação para o conhecimento seja, nesse caso, o tribunal da experiência (empiria) tomada a partir da verificação observacional, o modo de estruturação da proposição deve obedecer obrigatoriamente a normatividade das regras da lógica dedutiva.

O problema explícito das proposições científicas que não se deixam verificar pela observação, mesmo que sua forma lógica esteja correta, revela não somente o abismo que tem que ser transposto entre a linguagem natural e a científica, como também romper com as dificuldades epistemológicas geradas pelo confronto entre as teses realistas e antirrealistas sobre o que de fato é o 'mundo', o 'conhecimento sobre o mundo' e de como é possível justificar tais afirmações, se por apelo a razões epistêmicas, lógicas, pragmáticas ou empíricas.

Talvez, a fonte do relativismo ontológico e epistêmico, que normalmente surge do choque entre a abordagem realista e antirrealista, seja devido ao modo como a epistemologia normativa transcendental tenha se utilizado do modelo extraído de uma matriz de ordem física para o conhecimento.

A crítica do realismo científico que incide sobre o antirrealismo filosófico diria que o mundo ou a Natureza podem se ajustar aos esquemas conceituais do cientista, porque o realismo seja ele qual for (se científico ou filosófico) leva em conta que o seu empreendimento deve estar comprometido com a perspectiva que enfatiza a 'completa independência ontológica da realidade em relação aos nossos esquemas conceituais, crenças ou pontos de vista', sempre dentro da consideração de que a verdade é uma questão de correspondência (ou referência) entre as 
nossas crenças (científicas) e a realidade, isto é, a tese de que a verdade ou a falsidade de uma teoria é uma função de sua relação com um mundo "real" dado independentemente de uma mente - o relativismo ontológico e epistêmico surgiria da contraposição antirrealista acerca dessa tese, no sentido de que não há uma ontologia fixa do mundo em que teorias científicas sucessivas nos levam a aproximações cada vez melhores à verdade.

O antirrealismo, em seu sentido forte kantiano, mesmo ajuizando juízos sintéticos a priori como condições de possibilidade para a objetividade do conhecimento, circunscreve um 'mundo' no qual a sua 'materialidade' não pode ser garantida por nenhum juízo, porque não há na norma (universal) da causalidade nenhum mecanismo que revele a conexão necessária entre a 'causa e o efeito', a não ser pelo esquematismo das formas puras (a priori) da percepção e do entendimento, constitutivas do sujeito transcendental, que é lançado sobre o fenômeno. Sobre isso, acerca de tais condições de possibilidades para o conhecimento, diria um realista convicto: "Então, de fato nada sabemos, a não ser 'aquilo' que pomos no que desejamos conhecer".

É o 'mundo dado de modo independente da mente' que o realista deseja explicar. São a ontologia "real" do mundo em sua materialidade e suas "articulações" que o realismo intenta conhecer ou busca localizar - a ele interessa revelar o que é a "coisa-em-si" kantiana, isto é, 'aquilo' que se manifesta "por traz" do fenômeno informado e autorrepresentado na mente. Mas, um projeto epistemológico ou científico desta cepa seria possível realizar? Diria um realista convicto que sim, desde que se construa uma linguagem cujos termos teóricos ou científicos (observacionais ou não) estejam ajustados a uma correta teoria da correspondência ou da referência capaz de revelar não só a estrutura das teorias científicas, mas o seu funcionamento - nesse sentido, o realismo filosófico pode se aproximar em grande medida do realismo científico.

\section{CONSIDERAÇÕES FINAIS}

As tentativas neopositivistas utilizadas para superar o problema da conexão entre uma linguagem teórica e a linguagem observacional podem ser compreendidas como explicações que procuraram resolver o problema entre 0 realismo e o antirrealismo. Assim, o projeto epistemológico normativo calcado na 
filosofia analítica pode ser visto como um cálculo axiomático em que termos teóricos são interpretados por meio de regras de correspondência.

Entretanto, a abordagem normativa acerca dos processos epistemológicos parece ser insuficiente para uma correta e completa compreensão dos mecanismos epistemológicos, principalmente aqueles ligados à cognição.

Por consequência, a questão central em saber como os cientistas vinculam termos teóricos ou formas simbólicas ao mundo ou à Natureza continuou em aberto no seio da epistemologia normativa transcendental - o que tem possibilitado o surgimento de novas abordagens epistemológicas acerca do conhecimento científico, fundamentalmente aquelas cujas prerrogativas são de ordem naturalista, entre as quais podemos citar: a epistemologia naturalizada de Orman Quine, a epistemologia social de Steve Fuller, a epistemologia evolucionista de Karl Popper, a epistemologia tardia de Thomas Kuhn e as epistemologias evolucionistas construídas a partir dos programas epistemológicos intitulados de "evolução dos mecanismos epistemológicos (EME)" que fornece explicações do desenvolvimento das estruturas ou dos mecanismos cognitivos em animais e humanos, e do programa denominado de "epistemologia evolucionista das teorias (EET)" que tem por meta explicar o desenvolvimento do conhecimento, a evolução das ideias, das teorias científicas, das normas epistêmicas e da cultura em geral usando modelos de seleção e de metáforas extraídas da biologia evolucionista - todas entendidas aqui como projetos epistemológicos naturalistas ou descritivos que tentam superar em maior ou menor grau a normatividade ou o caráter prescritivo pressuposto no conhecimento ou nos mecanismos da cognição.

A título de pesquisas futuras que visam o confronto entre a abordagem normativa e a descritiva em epistemologia os trabalhos de Bradie, Harms e Gontier ${ }^{9}$ se constituem em importantes fontes bibliográficas para a temática e para a escritura de novos artigos.

\footnotetext{
${ }^{9}$ BRADIE, M. "Assessing evolutionary epistemology", in: Biology and philosophy, v. 1, pp. 401-459; "Evolutionary epistemology as naturalized epistemology", in: Issues in evolutionary epistemology, edited by K. Hahlweg and C. A. Hooker, 393-412. Albany, NY: SUNY Press; BRADIE, M., HARMS, W. (2005). "Evolutionary epistemology", in: The Stanford Encyclopedia of Philosophy. (Ed.) Edward N. Zalta, 2005; GONTIER, N. (2006). "Introduction to Evolutionary Epistemology, Language and Culture." In: Gontier, Nathalie, Van Bendegem, Jean Paul and Aerts, Diederik (eds), Evolutionary Epistemology, Language and Culture - A non-adaptationist systems theoretical approach, 01-29. Dordrecht: Springer, 2006.
} 


\section{REFERÊNCIAS}

BOGHOSSIAN, P. (2006). Fear of knowledge: against relativism and construtivismo. Oxford University Press, 2006.

KANT, I. (1781). Crítica da razão pura. Trad. Manuela Pinto dos Santos. Lisboa: Edição da Fundação Calouste Gulbenkian, 2001.

LAUDAN, L. (1996). Beyond positivism and relativism. Theory, method and evidence. Oxford: Westview Press, 1996.

PLATÂO. Teetetos - sobre o conhecimento, gênero comprobatório. Trad. de Carlos Alberto Nunes. Belém: Editora da Universidade Federal do Pará, 2001. 